\title{
Treatments in Chronic Cholestasis in Children
}

\author{
Fernando Alvarez \\ CHU Sainte-Justine, University of Montreal, Montreal, Qué., Canada
}

\section{Key Words}

Chronic cholestasis · Ursodeoxycholic acid · Rifampicin • lon exchange resins $\cdot \omega-3$ fatty acids $\cdot \mathrm{N}$-acetyl cysteine • Opioid antagonist

\begin{abstract}
Few specific treatments for children with chronic cholestasis are available. Most therapy strategies relieve bile component retention or palliate some of the consequences of chronic cholestasis. Ursodeoxycholic acid is the most frequently used pharmacological agent in children with chronic cholestasis. This bile acid is administered at dosages between 10 and $30 \mathrm{mg} / \mathrm{kg} /$ day to patients with cystic fibrosis, inborn errors of bile acid metabolism, progressive familial intrahepatic cholestasis, sclerosing cholangitis, biliary atresia, Alagille syndrome, or those receiving total parenteral nutrition. Ursodeoxycholic acid mainly increases bile flow and has a membrane-stabilizing effect, reducing the toxicity of more hydrophobic bile acids. Rifampicin, an antibiotic, at dosages between 10 and $20 \mathrm{mg} / \mathrm{kg} /$ day is very efficient in relieving pruritus. Similar effects are obtained using nonabsorbable ion exchange resins. In addition, these molecules decrease the serum cholesterol levels contributing to reduce xanthomas. Replacement of some deficiencies created by total parenteral nutrition by administration of essential fatty acids or cysteine can prevent or contribute to improve the associated liver disorders. In some cholestatic diseases, surgical procedures can help to relieve the obstacle to the bile flow, as it is the case for portoenterostomy in patients with
\end{abstract}

biliary atresia. In cases of intrahepatic cholestasis, a clinical and biochemical improvement can be recorded after bile diversion or other procedure (ileum exclusion) limiting the absorption of bile acids by the intestine. In the future, the association of these different pharmacological agents, increasing the bile flow, protecting cell membranes, or restoring nutritional deficiencies, could contribute to an improvement in quality of life in children with chronic cholestasis and eventually delay the need of a more drastic therapy such as liver transplantation. Advances in gene therapy and hepatocyte transplantation could also be of great help; however, many years of intense research are still necessary before even a pilot study using one of these therapies can be considered on liver diseases resulting in chronic cholestasis.

Copyright $\odot 2008$ Nestec Ltd., Vevey/S. Karger AG, Basel

Chronic cholestasis in children is the consequence of a large variety of causes, and very few of them have a specific treatment. In most cases, medical or surgical therapies have been developed to prevent or treat complications secondary to bile component retention. Existing treatments are mostly supportive, trying to reduce the accumulation of bile acids in the organism and its consequences: progressive liver fibrosis, pruritus, hyperlipidemia and fatigue.

Reduced quantities of bile acids in the lumen of the intestine are responsible for fat malabsorption. Steatorrhea can become a cause of malnutrition and liposoluble vitamin deficiency in chronic cholestasis. Some therapies

\section{KARGER \\ Fax +41613061234 \\ E-Mail karger@karger.ch}

www.karger.com
(C) 2008 Nestec Ltd., Vevey/S. Karger AG, Basel 0517-8606/08/0663-0127\$24.50/0

Accessible online at:

www.karger.com/ane
Prof. Fernando Alvarez, MD

Division of Gastroenterology, Hepatology and Nutrition

CHU Sainte-Justine, University of Montreal

3175, Cote Sainte-Catherine road, Montreal, Qué. H3T 1C5 (Canada)

E-Mail fernando.alvarez@umontreal.ca 
Table 1. Available treatments for chronic cholestasis in children

\begin{tabular}{|c|c|c|c|c|}
\hline Treatment & Indication & Contraindication & Side effects & Dosage \\
\hline UDCA & $\begin{array}{l}\text { influence on the } \\
\text { pathogenesis of PFIC, } \\
\text { CF, TPN; 'pruritus' }\end{array}$ & $\begin{array}{l}\text { obstruction of bile ducts } \\
\text { (e.g., failure of portoen- } \\
\text { terostomy in BA) }\end{array}$ & diarrhea & $20-30 \mathrm{mg} / \mathrm{kg} /$ day \\
\hline Rifampicin & 'pruritus' & mycobacterium infection $^{1}$ & & $10-20 \mathrm{mg} / \mathrm{kg} /$ day \\
\hline $\begin{array}{l}\text { Nonabsorbable } \\
\text { ion exchange resins }\end{array}$ & $\begin{array}{l}\text { 'pruritus' } \\
\text { hypercholesterolemia }\end{array}$ & $\begin{array}{l}\text { intestinal stenosis or } \\
\text { subocclusion }\end{array}$ & $\begin{array}{l}\text { constipation } \\
\text { hyperchloremic } \\
\text { acidosis }\end{array}$ & $\begin{array}{l}8-16 \text { g orally daily divided in } 2-3 \\
\text { times (increased progressively from } \\
2 \mathrm{~g} \text { orally daily) }\end{array}$ \\
\hline Opioid antagonists & 'pruritus' & - & $\begin{array}{l}\text { withdrawal } \\
\text { reactions }\end{array}$ & $?$ \\
\hline$\omega-3$ fatty acids & $\begin{array}{l}\text { TPN-induced } \\
\text { liver disease }\end{array}$ & - & - & $\begin{array}{l}1 \mathrm{~g} / \mathrm{kg} / \text { day (increased progressively } \\
\text { from } 0.2 \mathrm{mg} / \mathrm{kg} / \text { day) }\end{array}$ \\
\hline NAC & $\begin{array}{l}\text { TPN-induced } \\
\text { liver disease }\end{array}$ & - & - & $\begin{array}{l}70-135 \mathrm{mg} / \mathrm{kg} / \text { day (increased } \\
\text { progressively from } 20 \mathrm{mg} / \mathrm{kg} / \text { day) }\end{array}$ \\
\hline
\end{tabular}

Associations of some of these drugs are usually required. BA = Biliary atresia.

described below, aiming to avoid the enterohepatic recirculation of bile acids, can aggravate this situation.

Pharmacological agents such as ursodeoxycholic acid (UDCA) and rifampicin improve choleresis by enhancing hepatocyte excretion of bile acids. Nonabsorbable ion exchange resins bind bile acids in the lumen of the intestine, decreasing its enterohepatic circulation. All these drugs increase choleresis and diminish pruritus and levels of cholesterol. Opioid antagonists have been proposed to treat pruritus; however, their limited availability, as well as their side effects, restricted their use in pediatrics (table 1).

Surgical interventions can be curative, as the Kasai intervention in some patients with biliary atresia, or palliative as the partial biliary diversion and the ilial exclusion in patients with Alagille syndrome or progressive familial intrahepatic cholestasis (PFIC). The latter could improve pruritus, decrease cholesterol retention and prevent evolution to cirrhosis.

\section{Ursodeoxycholic Acid}

UDCA ( $3 \alpha, 7 \beta$-dihydroxy-5 $\beta$-cholan-24-oic acid) is present in small quantities in human bile, up to $3 \%$, and is the result of the $7 \beta$ epimerization of chenodeoxycholic acid by colonic bacteria [1].
The $\beta$ rather than the $\alpha$ hydroxy group at the 7 th position gives UDCA a higher hydrophilicity when compared with chenodeoxycholic acid, its precursor. Thus, because of less hydrophobicity, UDCA is poor at micelle formation. In addition, it is poorly absorbed in the proximal intestine [1].

\section{Mechanisms of Action}

- Replacement of more hydrophobic bile acids at the circulating pool and at cell membranes. After 6 months of treatment at $10-12 \mathrm{mg} / \mathrm{kg} / \mathrm{day}$, UDCA represents $40-50 \%$ of the bile acid pool [2]. Because of their detergent capabilities, more hydrophobic bile acids are toxic for cell membranes, causing hepatocellular damage and an increase in cholestasis. UDCA has a membrane-stabilizing effect, reducing disruption of cholesterol-rich membranes [3].

- UDCA, but not its conjugated form taurodeoxycholate, decreases the toxicity of lipophilic bile acids on the function of the electron transport chain in a concentration-dependent form (up to $100 \mu \mathrm{mol} / \mathrm{l}$ ), but increases bile acid-induced mitochondrial toxicity at higher concentrations [4].

- Interference in the ileum with the absorption of more toxic bile acids [2].

- UDCA is reabsorbed by the biliary epithelium in a protonated form and it is secreted again into bile (cholehepatic shunt) producing a hypercholeretic effect. 
The protons absorbed lead to the formation of bicarbonate that is secreted and enrich the bile in this component [2].

- UDCA increases the bile salt-independent flow $[1,2]$.

- UDCA may stimulate transporter expression at the canalicular hepatocyte surface [5].

- A reduction in human leukocyte antigen class I expression at the hepatocyte surface has been reported [6].

- UDCA also suppresses interferon- $\gamma$-mediated induction of human leukocyte antigen class II expression via the glucocorticoid receptor-mediated pathway [7]. UDCA is responsible for very few and transitory side effects, such as diarrhea and skin reactions more probably due to drug adjuvants than to the active substance. However, it should be avoided or carefully administered to patients with an obstructive bile duct disease. In experimental animals with a ligation of the main bile duct, UDCA can aggravate bile infarcts [8]. In children with biliary atresia and unsuccessful Kasai intervention, UDCA can precipitate a liver failure.

UDCA is the most frequent drug used in children with chronic cholestasis. In several diseases, the benefit of the long-term administration of UDCA has not been proven beyond any doubt, as is the case for cystic fibrosis (CF). In other cases, the administration of the drug improves liver tests, but not the final outcome, as in patients with sclerosing cholangitis. In PFIC, it appears to stop the progression of the disease in some children and, associated with cholic acid, it is the treatment of choice in patients with inborn errors of the bile acid metabolism. In children with Alagille syndrome or biliary atresia, UDCA is mainly used to reduce symptoms such as pruritus.

\section{Cystic Fibrosis}

After 2 months of UDCA therapy, the presence of this bile acid represents between 25 and $42 \%$ of the pool, at the expense of cholic and chenodeoxycholic acids; these differences are dose dependent [9]. From these studies, it was concluded that the recommended dosage of UDCA is $20 \mathrm{mg} / \mathrm{kg} /$ day or greater [9].

UDCA stimulates the biliary secretory capacity in livers of CF patients, as determined by hepatobiliary scintigraphy [10]. Several pilot studies have shown that UDCA is responsible for an improvement in biochemical tests, mainly a decrease in serum levels of aminotransferases (ALT and AST) and $\gamma$-glutamyl transferase (GGT) [11]. In addition, liver inflammation and/or bile duct proliferation were improved after 2 years of UDCA therapy in control biopsies. UDCA administration also improves the nutritional state of young adults with CF and, in chil- dren, ameliorates essential fatty acids and retinol status [12-14]. However, because of poor UDCA activity in micelle formation it did not affect steatorrhea [13]. If UDCA modifies the natural history of liver diseases in CF patients, it still remains to be studied in a large randomized prospective study. Encouraging results were recently reported on UDCA-induced arrest or even reversion of liver ultrasound lesions observed in patients with $\mathrm{CF}$, in a long-term study [15].

\section{Total Parenteral Nutrition}

Fasting associated with total parenteral nutrition (TPN) leads to bile stasis related to lack of stimulation of the bile acid-dependent and -independent bile flow. In a model of TPN-induced cholestasis, the intravenous administration of UDCA improved bile flow and reduced bilirubin levels [16]. Similar encouraging results were recorded in a pilot study of children with intractable diarrhea depending on TPN, but tolerating UDCA at the dosage of $30 \mathrm{mg} / \mathrm{kg} /$ day in 3 daily doses [17].

In very low birth weight infants with $\mathrm{TPN}$-associated cholestasis, UDCA at doses of $10-30 \mathrm{mg} / \mathrm{kg} /$ day reduces the duration and intensity of cholestasis [18]. In most of these patients, intestinal complications, including partial resections of the bowel, preclude the standard use of UDCA. Eventually, a very fractionated daily dosage of the medication can be well tolerated, avoiding diarrhea. Unfortunately, the UDCA intravenous form is not commercially available.

\section{Inborn Errors of Bile Acid Metabolism}

Two main forms of bile acid synthesis defect are responsible for chronic cholestasis in children: the 3-oxo$\Delta 4$-steroid $5 \beta$-reductase deficiency and the $3 \beta$-hydrosteroid- $\Delta 5$-oxireductase/isomerase deficiency. Hepatotoxicity is probably due to the accumulation of bile acid precursors and the lack of primary bile acids. To reduce the synthesis of toxic molecules, the activity of cholesterol $7 \alpha$ hydroxylase, the rate-limiting enzyme in endogenous bile acid synthesis, must be inhibited.

Most patients respond only partially to UDCA treatment alone; association of cholic acid ( $250 \mathrm{mg} /$ day) is therefore indicated. The administration of chenodeoxycholic and cholic acids has also been proposed in these patients. The latter treatment can lead to a faster improvement in the liver injury [19].

\section{Progressive Familial Intrahepatic Cholestasis}

UDCA is a valuable initial treatment for patients with PFIC when administered orally at doses between 20 and 
$30 \mathrm{mg} / \mathrm{kg} /$ day. Similar improvement was observed no matter the PFIC type, meaning patients with normal (PFIC types 1 and 2) or increased levels (PFIC type 3 ) of serum GGT. In patients with normal GGT, an improvement in parameters of cholestasis was observed in $61 \%$ of cases and in $71 \%$ of those with type 3 PFIC [20]. The duration of the disease prior to the beginning of the UDCA treatment could influence these results; early diagnosis and initiation of UDCA therapy could further improve the final outcome. In some patients, the improvement, even if complete, is only transitory, and the cholestasis reappears some years after the beginning of UDCA.

In patients with less deleterious mutations in genes responsible for types 1 or 2 of PFIC, a benign recurrent intrahepatic cholestasis is observed. In benign recurrent intrahepatic cholestasis patients, UDCA treatment fails in preventing a cholestatic episode, but could improve some of the symptoms (e.g., pruritus) [21].

\section{Sclerosing Cholangitis}

An initial pilot study of UDCA in patients with welldeveloped sclerosing cholangitis showed an improvement in liver tests. Later, a statistically significant difference in the serum levels of ALT/AST/GGT was observed between UDCA and placebo-treated patients with sclerosing cholangitis during a study of 3 years of follow-up [22]. An improvement in pruritus and fatigue was also observed, but the difference was not significant. Unfortunately, more recent results in a randomized, doubleblind study comparing UDCA (13-15 mg/kg/day) with placebo showed no differences in treatment failure (progression of the disease, death or liver transplantation). This study confirmed an improvement in liver tests, but concluded that UDCA did not offer clinical benefits to patients with sclerosing cholangitis [23]. Thus, low dosages of UDCA apparently do not modify the progression of this disease. A very recently published study showed that, on the contrary, high doses of UDCA were associated with an improvement in survival and a trend toward stability/improvement in the histological stage in a relatively small group of patients with sclerosing cholangitis [24].

Despite these results, new trials could be proposed using high dosages of UDCA very early in the evolution of sclerosing cholangitis, and particularly in patients with small duct disease. When the disease affects the main bile ducts (as in most cases), probably, the disturbance in the bile flow can contribute irreversibly to the aggravation of the liver disease. The larger experience in the use of UDCA in chronic cholestatic diseases was obtained in adult patients with primary biliary cirrhosis, a severe form of intrahepatic cholangiopathy [25]. Different groups showed controversial results with UDCA therapy, partially explained by the different time in the evolution of the disease at the starting of treatment. The dose of UDCA administered also appears to play a role in the influence of this medication on the final outcome. This vast experience should be considered in planning new trials in patients with sclerosing cholangitis.

\section{Biliary Atresia}

An early preliminary study using UDCA after hepatic portoenterostomy showed that this drug was effective in patients with a good postoperative bile drainage, resulting in lower total bile acid levels and better weight gain [26]. Long-term administration of UDCA significantly improves the final outcome after Kasai portoenterostomy, more patients cleared jaundice and survived with their native liver. In children without recovery of a good bile flow after portoenterostomy, UDCA administration can lead to faster development of liver injury, and eventually, precipitates a liver failure [27].

\section{Alagille Syndrome}

Few reports are available on the use of UDCA in patients with Alagille syndrome. Improvement in the jaundice and pruritus was found, as well as a decrease in circulating lipid levels and a decrease in xanthomas [28]. No controlled study is available; however, UDCA is widely prescribed to these patients. The influence of this bile acid in the natural history of the disease is still unknown.

\section{Rifampicin}

Rifampicin decreases the bile acid concentration in hepatocytes, by competing with its uptake. Furthermore, this antibiotic induces microsomal enzymes that promote the $6 \alpha$-hydroxylation and subsequent $6 \alpha$-glucuronidation of toxic bile acid.

Initial clinical experience using this antibiotic for the treatment of pruritus was given in adults with a primary biliary cirrhosis, showing a significant relief from pruritus in a majority of patients [29]. In children with chronic cholestasis, a double-blind crossover study showed the efficacy of rifampicin in alleviating pruritus during a period of up to 6 months [30]. Subsequently, 2 studies on pediatric patients with refractory pruritus treated by rifampicin confirmed those initial results $[31,32]$. No im- 
provement in biochemical features of cholestasis was recorded in most treated children with different causes of chronic cholestasis.

The recommended dosage of rifampicin is $10-20 \mathrm{mg} /$ $\mathrm{kg} /$ day in 2 daily doses. Few side effects were reported. However, rifampicin is an enzymatic inducer of microsomal enzymes. Several forms of cytochrome P450 isoenzyme activity are increased by rifampicin administration; therefore, the rate of metabolism of several drugs can be accelerated.

It was proposed that UDCA and rifampicin have complementary effects that may justify a combination of both agents in the treatment of patients with cholestatic diseases [33].

\section{Nonabsorbable Ion Exchange Resins}

These molecules are not absorbable from the gastrointestinal tract and release chloride and bind bile acids in the lumen of the intestine, diminishing their enterohepatic recirculation. Nonabsorbable ion exchange resins augment cholesterol excretion via enhanced conversion to bile acids. These drugs can decrease the bile acid pool by approximately $40 \%$. Trihydroxy bile acid dissociates rapidly from these molecules and can be absorbed in the ileum.

Cholestyramine (orange-flavored granules) has been used for some decades and has been proven to be effective and safe. However, palatability is poor, limiting the tolerability to this drug. Therefore, compliance is erratic in the best of cases. When nasogastric tubes are indicated for enteral feeding, the administration of cholestyramine through this pathway has been shown to be well tolerated and successful in decreasing serum cholesterol levels and improving pruritus (fig. 1).

In children, cholestyramine can be started at a dosage of 2-4 g twice daily and then increased to 8-16 g daily in 2 or 3 divided doses. Cholestyramine binds other acids or negatively charged substances, which explains most of its interaction with many drugs.

Colestipol in granules or tablets has not been used frequently in children. Indications and precautions in its use are similar to those described for cholestyramine.

Colesevelam hydrochloride (in the form of a nonabsorbable hydrogel or tablet) is probably the best tolerated of these drugs, but unfortunately, it is not available everywhere [34]. This drug has enhanced the specificity, greater affinity and higher capacity for binding bile acids compared with the 2 other nonabsorbable ion exchange resins mentioned above.

Treatments in Cholestasis

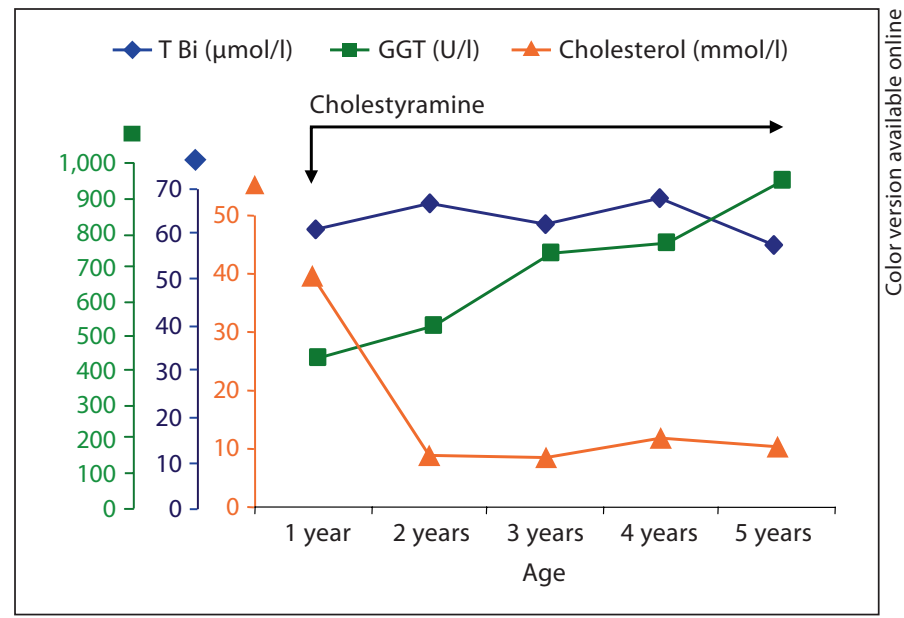

Fig. 1. In this boy with Alagille syndrome, cholestyramine was administered by a nasogastric tube, indicated for enteral feeding. Dramatic decrease in serum cholesterol levels and shrinking of xanthomas was observed. Pruritus improved with the association of rifampicin with the treatment. No modifications in biochemical parameters of cholestasis were recorded.

Nonabsorbable ion exchange resins can interfere with the intestinal absorption of other drugs, like UDCA. This particular problem should be considered when treating a patient with chronic cholestasis. In addition, the time of administration should be well established to allow a maximal capture of bile acids and to avoid interaction with other drugs including fat-soluble vitamins. Other drugs should be given 1 or $4-6 \mathrm{~h}$ after cholestyramine.

Main side effects are constipation and hyperchloremic acidosis due to the large quantities of chloride released in the gastrointestinal lumen and absorbed instead of bicarbonate. The latter can be particularly severe in patients with Alagille syndrome, frequently showing previous renal problems.

\section{Opioid Antagonists}

Naloxone and nalmefene are the first 2 opioid antagonists tested in adults with primary biliary cirrhosis, attempting to relieve pruritus $[35,36]$. The use of these substances was based on the possible role of the central nervous system in the pruritus observed in patients with cholestasis. Enkephalin class substances (endogenous opioids) may be potential mediators in the involvement of the nervous system.

Ann Nestlé [Engl] 2008;66:127-135 


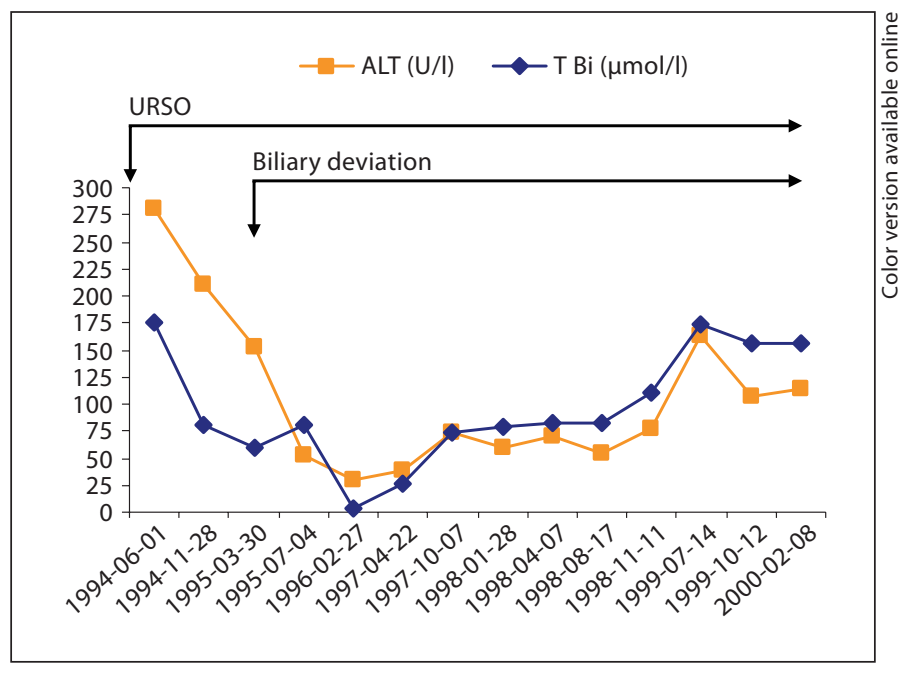

Fig. 2. In this girl with PFIC (low GGT), a partial biliary deviation was carried out. An almost complete normalization of biochemical liver tests was recorded. Relapse of symptoms and signs of cholestasis were observed 2-3 years after surgery. Hepatobiliary scintigraphy showed that the bile flow was almost exclusively directed to the stoma bag. This case showed that the liver disease progressed despite bile diversion and UDCA treatment.

A placebo-controlled single-blinded trial of naloxone proved that this medication reduced the scratching activity in cholestatic patients. The main problems with this drug were the need of intravenous perfusions due to its very short half-life and a possible opiate withdrawal syndrome at the end of the perfusion [35].

Nalmefene can be administered orally (but this form is not available everywhere). Improvement in the perception of pruritus was reported in most treated patients because of its longer duration of action when compared with naloxone. This medication can be associated with severe withdrawal symptoms, which is apparently dependent on the dosage used. Marked exarcebation of pruritus when the drug was suddenly discontinued was also reported [36].

Naltrexone can also be administered orally. In a randomized trial of naltrexone versus placebo, a significant decrease in daytime and nighttime itching was reported. Opiate withdrawal syndrome was observed in half of the patients receiving naltroxone [37].

No series on the use of opioid antagonists in children with chronic cholestasis has been published. Therefore, it is impossible to conclude on its indication in the pediatric population. From adult experiences, these drugs are dif- ficult to administer and it is hard to avoid side effects when discontinued.

\section{$\omega-3$ Fatty Acids}

Liver disease associated with TPN in children with intestinal failure can lead to cirrhosis and liver failure. In some patients, when UDCA is absorbed, an improvement in liver tests has been recorded. More spectacular results were obtained by replacing soy oils in fat emulsions with fish oils. Children receiving a solution enriched in $\omega-3$ fatty acids showed a dramatic improvement in the liver disease [38].

Recently, a 4-year-old boy followed at our institution had a resection of most of his small intestine, because of a volvulus. This child developed a severe liver disease on TPN and was enrolled on the waiting list for a liver transplant. Parenteral fish oil was started (Omegaven), and 3 months later, he was removed from the waiting list, and 6 months later, showed normal serum levels of conjugated bilirubin [V. Marchand, pers. commun.].

\section{N-Acetyl Cysteine}

Liver disease in the long-term TPN population is the consequence of a variety of factors. Oxidative stress appears to play a major role in the etiology and in the persistence and aggravation of cholestasis. Cellular concentrations of glutathione is an essential defense against this harmful process. Cysteine is an important precursor of intracellular glutathione; however, low levels of cysteine are found in currently used aminoacid solution.

$\mathrm{N}$-acetyl cysteine (NAC) can be used as a precursor of cysteine. When NAC was added to the parenteral nutrition solution, at dosages of $70-135 \mathrm{mg} / \mathrm{kg} / \mathrm{day}$, a normalization or marked decrease in serum-conjugated bilirubin levels was recorded [39]. This improvement in liver cholestasis was associated with a normalization of glutathione in red blood cells, suggesting that the cellular concentration of this antioxidant molecule played a major role in the decrease in the liver injury.

\section{Surgical Procedures}

\section{Biliary Diversion and Ileal Exclusion}

More than 30 years ago, Alagille and Odièvre, at Bicêtre Hospital in France, described the efficacy of bili- 
ary drainage by cholecystostomy in patients with PFIC and Alagille syndrome. Unfortunately, because of local complications on the skin around the drain, this type of external bile drainage could not be kept for a long time [40].

In the 80 s, a technique of partial biliary diversion was developed, using $10-15 \mathrm{~cm}$ of jejunum interposed between the gallbladder and the skin. This procedure was permanent and allowed the partial deviation of the bile flow to an external stoma bag for years. A clinical and biochemical improvement was reported in patients with Alagille syndrome [41]. In children with PFIC, the partial biliary diversion resulted in an improvement in growth, relief of pruritus and correction of biochemical anomalies of cholestasis $[42,43]$. In some cases, the dramatic improvement was transitory, followed by a relapse of the cholestasis and the requirement of liver transplantation after 4-5 years of the initial bile deviation (personal observations) (fig. 2). In other cases, the complete improvement was only obtained if UDCA was given as a coadjuvant therapy.

A technical variant was later reported, in which the appendix vermiformis was used as a conduit between the gallbladder and the skin, with very good results [44].

In a recent publication, another way of obtaining a partial deviation of the bile flow was described. In 3 patients with Alagille syndrome, $15 \%$ of the terminal ileum was excluded using a stapled division and ileocecal anastomosis. The rationale of the procedure is to avoid the site of maximal absorption of bile acids in the bowel. A decrease in cholesterol levels, an improvement in pruritus and a reduction in xanthomes sizes were observed [45].

All of these surgical procedures should be avoided in patients that have already developed a cirrhosis. Important bleeding from neo-varices at sites of anastomosis is a very frequent complication. In addition, in patients with advanced liver disease, the benefits of such procedures are not demonstrated.

\section{Hepaticoportoenterostomy}

The surgical intervention described by Kasai in the 1950 s became the first and only procedure able to restore the bile flow in patients with biliary atresia.

Normalization of serum bilirubin, within 3 months of portoenterostomy, has been found to indicate a good long-term prognosis. This occurs in around $50-60 \%$ of operated infants, with a better outcome when the inter- vention has been carried out early in life [46]. Other factors at the time of the portoenterostomy can modify the final outcome such as the degree of the liver fibrosis and the characteristics of the extrahepatic remnant. The prognosis of the Kasai intervention in a patient with polysplenia malformation syndrome associated with biliary atresia has been worse in some centers and similar to biliary atresia without malformations in others [47]. In the postoperatory period, the development of cholangitis can also worsen the prognosis.

Because of the presence of inflammatory infiltrate in the liver of these patients, it was proposed that the use of anti-inflammatory drugs could arrest the progression of the disease. Unfortunately, several recent publications of pilot and double-blind randomized studies showed that the use of high doses of steroids after Kasai intervention did not increase survival of the native liver $[48,49]$.

Ten-year survival is between 30 and $54 \%$ in different centers around the world; around $25 \%$ at 20 years, and $10 \%$ at 30 years [50-53]. All patients develop a cirrhosis, with the associated complications of portal hypertension: gastrointestinal bleeding, hypersplenism and hepatopulmonary diseases.

Liver transplantation has improved the overall survival of children with biliary atresia and failure of the Kasai intervention. Currently, the success of this therapy is responsible for a survival rate of $90 \%$ [47].

\section{Perspectives}

Eventually, 2 future therapies could definitely cure some inherited diseases responsible for chronic cholestasis: gene therapy and/or hepatocyte transplantation. In the case of gene therapy, after initial years of hope, disappointing results in most trials and serious side effects relented its progression and further development. In the case of the liver, it is not known how many cells should express a specific gene to avoid the development of symptoms and signs of a particular disease and impede its progression. Many problems need to be solved before we can even think of a trial concerning a cholestatic liver disease.

Hepatocyte transplantation has already been attempted in some human beings. Partial correction of liver-inherited diseases was observed in animal models. Normal hepatocytes have an advantage over the repopulation of the liver against cells carrying a mutated and possibly lethal gene. Correction of the PFIC type 3 in a mouse model was reported and stayed stable for a long time [54]. This 
therapy is confronted with the availability of normal hepatocytes, the need of immunosuppressive therapy and the question on the fate of remaining mutated cells. The risk of tumors developing in the long-term follow-up represents a considerable concern.

The use of $\omega-3$ fatty acid cholestasis of different origins should be explored. Deficiency in essential fatty acids has been reported in patients with cholestasis of different etiologies, e.g., Alagille syndrome and CF. This feature is most probably a consequence of severe steatorrhea. Extraintestinal pathways of administration have been proposed, but without much success. Intravenous, periodic administration could be indicated in some cases.

Oxidative stress is almost constantly associated with cholestasis. It can be hypothesized that in these children, the retention of bile components, the malabsorption responsible for malnutrition and deficiency of essential fat- ty acids and oligoelements lead to malformation of different cellular mechanisms of protection. In the latter, the deficiency in glutathione can be included. NAC administration could be of great help in several cholestatic processes, as an adjuvant therapy.

Future trials should test the potential benefit of $\omega-3$ fatty acids and NAC in children with chronic cholestasis. Both of these therapies show very few side effects, being well tolerated in children.

Many of the drugs described above could be associated in the treatment of chronic cholestasis in order to diminish the liver injury and/or to relieve harmful symptoms of these disorders. Drugs with different mechanisms of action can be associated with an adequate nutritional support, individualizing the therapy according to the etiology of the cholestasis and the current status of a particular child.

\section{References}

1 Heuman DM: Hepatoprotective properties of ursodeoxycholic acid. Gastroenterology 1993;104:1865-1870.

-2 Beuers U, Boyer JL, Paumgartner G: Ursodeoxycholic acid in cholestasis: potential mechanisms of action and therapeutic applications. Hepatology 1998;28:1449-1453.

$\checkmark 3$ Heuman DM, Bajaj R: Ursodeoxycholate conjugates protect against disruption of cholesterol-rich membranes by bile salts. Gastroenterology 1994;106:1333-1341.

4 Krahenbuhl S, Fischer S, Talos C, Reichen J: Ursodeoxycholate protects oxidative mitochondrial metabolism from bile acid toxicity: dose-response study in isolated rat liver mitochondria. Hepatology 1994;20:15951601.

5 Fickert P, Zollner G, Fuchsbichler A, et al: Effects of ursodeoxycholic and cholic acid feeding on hepatocellular transporter expression in mouse liver. Gastroenterology 2001;121:170-183.

-6 Terasaki S, Nakanuma Y, Ogino H, et al: Hepatocellular and biliary expression of HLA antigens in primary biliary cirrhosis before and after ursodeoxycholic acid therapy. Am J Gastroenterol 1991;86:1194-1199.

7 Tanaka H, Makino Y, Miura T, et al: Ligandindependent activation of the glucocorticoid receptor by ursodeoxycholic acid. Repression of IFN-gamma-induced MHC class II gene expression via a glucocorticoid receptor-dependent pathway. J Immunol 1996; 156:1601-1608.
-8 Fickert P, Zollner G, Fuchsbichler A, et al: Ursodeoxycholic acid aggravates bile infarcts in bile duct-ligated and Mdr2 knockout mice via disruption of cholangioles. Gastroenterology 2002;123:1238-1251.

$\checkmark 9$ Colombo C, Crosignani A, Assaisso M, et al: Ursodeoxycholic acid therapy in cystic fibrosis-associated liver disease: a dose-response study. Hepatology 1992;16:924-930.

10 Colombo C, Castellani MR, Balistreri WF, et al: Scintigraphic documentation of an improvement in hepatobiliary excretory function after treatment with ursodeoxycholic acid in patients with cystic fibrosis and associated liver disease. Hepatology 1992;15: 677-684.

$\checkmark 11$ Colombo C, Setchell KD, Podda M, et al: Effects of ursodeoxycholic acid therapy for liver disease associated with cystic fibrosis. J Pediatr 1990;117:482-489.

12 Lindblad A, Glaumann H, Strandvik B: A two-year prospective study of the effect of ursodeoxycholic acid on urinary bile acid excretion and liver morphology in cystic fibrosis-associated liver disease. Hepatology 1998;27:166-174.

13 Cotting J, Lentze MJ, Reichen J: Effects of ursodeoxycholic acid treatment on nutrition and liver function in patients with cystic fibrosis and longstanding cholestasis. Gut 1990;31:918-921.

14 Lepage G, Paradis K, Lacaille F, et al: Ursodeoxycholic acid improves the hepatic metabolism of essential fatty acids and retinol in children with cystic fibrosis. J Pediatr 1997; 130:52-58
15 Nousia-Arvanitakis S, Fotoulaki M, Economou $\mathrm{H}$, et al: Long-term prospective study of the effect of ursodeoxycholic acid on cystic fibrosis-related liver disease. J Clin Gastroenterol 2001;32:324-328.

16 Duerksen DR, Van Aerde JE, Gramlich L, et al: Intravenous ursodeoxycholic acid reduces cholestasis in parenterally fed newborn piglets. Gastroenterology 1996;111:11111117.

17 Spagnuolo MI, Iorio R, Vegnente A, Guarino A: Ursodeoxycholic acid for treatment of cholestasis in children on long-term total parenteral nutrition: a pilot study. Gastroenterology 1996;111:716-719.

18 Chen CY, Tsao PN, Chen HL, et al: Ursodeoxycholic acid (UDCA) therapy in very-lowbirth-weight infants with parenteral nutrition-associated cholestasis. J Pediatr 2004; 145:317-321.

19 Clayton PT, Mills KA, Johnson AW, et al: Delta 4-3-oxosteroid 5 beta-reductase deficiency: failure of ursodeoxycholic acid treatment and response to chenodeoxycholic acid plus cholic acid. Gut 1996;38:623-628.

20 Jacquemin E, Hermans D, Myara A, et al: Ursodeoxycholic acid therapy in pediatric patients with progressive familial intrahepatic cholestasis. Hepatology 1997;25:519-523.

21 Crosignani A, Podda M, Bertolini E, et al: Failure of ursodeoxycholic acid to prevent a cholestatic episode in a patient with benign recurrent intrahepatic cholestasis: a study of bile acid metabolism. Hepatology 1991;13: 1076-1083. 
22 Stiehl A, Walker S, Stiehl L, et al: Effect of ursodeoxycholic acid on liver and bile duct disease in primary sclerosing cholangitis. A 3 -year pilot study with a placebo-controlled study period. J Hepatol 1994;20:57-64.

-23 Lindor KD: Ursodiol for primary sclerosing cholangitis. Mayo Primary Sclerosing Cholangitis-Ursodeoxycholic Acid Study Group. N Engl J Med 1997;336:691-695.

-24 Cullen SN, Rust C, Fleming K, et al: High dose ursodeoxycholic acid for the treatment of primary sclerosing cholangitis is safe and effective. J Hepatol 2008;48:792-800.

$\checkmark 25$ Corpechot C, Carrat F, Bahr A, et al: The effect of ursodeoxycholic acid therapy on the natural course of primary biliary cirrhosis. Gastroenterology 2005;128:297-303.

26 Nittono H, Tokita A, Hayashi M, et al: Ursodeoxycholic acid in biliary atresia. Lancet 1988;1:528.

-27 Stringer MD, Davison SM, Rajwal SR, McClean P: Kasai portoenterostomy: 12-year experience with a novel adjuvant therapy regimen. J Pediatr Surg 2007;42:1324-1328.

-28 Krawinkel MB, Santer R, Oldigs HD: Ursodesoxycholic acid: effect on xanthomas in Alagille-Watson syndrome. J Pediatr Gastroenterol Nutr 1994;19:476-477.

-29 Bachs L, Parés A, Elena M, et al: Comparison of rifampicin with phenobarbitone for treatment of pruritus in biliary cirrhosis. Lancet 1989;1:574-576.

30 Cynamon HA, Andres JM, Iafrate RP: Rifampin relieves pruritus in children with cholestatic liver disease. Gastroenterology 1990;98:1013-1016.

-31 Gregorio GV, Ball CS, Mowat AP, Mieli-Vergani G: Effect of rifampicin in the treatment of pruritus in hepatic cholestasis. Arch Dis Child 1993;69:141-143.

-32 Yerushalmi B, Sokol RJ, Narkewicz MR, et al: Use of rifampin for severe pruritus in children with chronic cholestasis. J Pediatr Gas troenterol Nutr 1999;29:442-447.

-33 Marschall HU, Wagner M, Zollner G, et al: Complementary stimulation of hepatobiliary transport and detoxification systems by rifampicin and ursodeoxycholic acid in humans. Gastroenterology 2005;129:476-485.
34 Aldridge MA, Ito MK: Colesevelam hydrochloride: a novel bile acid-binding resin. Ann Pharmacother 2001;35:898-907.

-35 Bergasa NV, Talbot TL, Alling DW, et al: A controlled trial of naloxone infusions for the pruritus of chronic cholestasis. Gastroenterology 1992;102:544-549.

36 Bergasa NV, Schmitt JM, Talbot TL, et al: Open-label trial of oral nalmefene therapy for the pruritus of cholestasis. Hepatology 1998;27:679-684.

$\checkmark 37$ Wolfhagen FH, Sternieri E, Hop WC, et al: Oral naltrexone treatment for cholestatic pruritus: a double-blind, placebo-controlled study. Gastroenterology 1997;113:12641269 .

38 Gura KM, Duggan CP, Collier SB, et al: Reversal of parenteral nutrition-associated liver disease in two infants with short bowe syndrome using parenteral fish oil: implications for future management. Pediatrics 2006;118:e197-e201.

39 Mager DR, Marcon M, Wales P, Pencharz PB: Use of $\mathrm{N}$-acetyl cysteine for the treatment of parenteral nutrition-induced liver disease in children receiving home parenteral nutrition. J Pediatr Gastroenterol Nutr 2008;46: 220-223.

40 Alagille D, Odievre M: Les cholestases de l'enfant. Maladies du foie et des voies biliaires chez l'enfant. Paris, Flammarion, 1978.

41 Emerick KM, Whitington PF: Partial external biliary diversion for intractable pruritus and xanthomas in Alagille syndrome. Hepatology 2002;35:1501-1506.

42 Melter M, Rodeck B, Kardorff R, et al: Progressive familial intrahepatic cholestasis: partial biliary diversion normalizes serum lipids and improves growth in noncirrhotic patients. Am J Gastroenterol 2000;95:35223528.

43 Kurbegov AC, Setchell KD, Haas JE, et al: Biliary diversion for progressive familial intrahepatic cholestasis: improved liver morphology and bile acid profile. Gastroenterology $2003 ; 125: 1227-1234$.
44 Gauderer MW, Boyle JT: Cholecystoappendicostomy in a child with Alagille syndrome. J Pediatr Surg 1997;32:166-167.

45 Modi BP, Suh MY, Jonas MM, et al: Ileal exclusion for refractory symptomatic cholestasis in Alagille syndrome. J Pediatr Surg 2007; 42:800-805.

46 Ohhama Y, Shinkai M, Fujita S, et al: Early prediction of long-term survival and the timing of liver transplantation after the Kasai operation. J Pediatr Surg 2000;35:10311034.

47 Chardot C, Serinet MO: Prognosis of biliary atresia: what can be further improved? J Pediatr 2006;148:432-435.

48 Davenport M, Stringer MD, Tizzard SA, et al: Randomized, double-blind, placebo-controlled trial of corticosteroids after Kasai portoenterostomy for biliary atresia. Hepatology 2007;46:1821-1827.

49 Petersen C, Harder D, Melter M, et al: Postoperative high-dose steroids do not improve mid-term survival with native liver in biliary atresia. Am J Gastroenterol 2008;103:712719.

50 McKiernan PJ, Baker AJ, Kelly DA: The frequency and outcome of biliary atresia in the UK and Ireland. Lancet 2000;355:25-29.

51 Chardot C, Carton M, Spire-Bendelac N, et al: Prognosis of biliary atresia in the era of liver transplantation: French national study from 1986 to 1996. Hepatology 1999;30:606611.

52 Shneider BL, Brown MB, Haber B, et al: A multicenter study of the outcome of biliary atresia in the United States, 1997 to 2000. J Pediatr 2006;148:467-474.

53 Schreiber RA, Barker CC, Roberts EA, et al: Canadian Pediatric Hepatology Research Group. Biliary atresia: the Canadian experience. J Pediatr 2007;151:659-665.

54 De Vree JM, Ottenhoff R, Bosma PJ, et al: Correction of liver disease by hepatocyte transplantation in a mouse model of progressive familial intrahepatic cholestasis. Gastroenterology 2000;119:1720-1730. 